\title{
Tidal modulation of ice-shelf flow: a viscous model of the Ross Ice Shelf
}

\author{
Kelly M. BRUNT, ${ }^{1}$ Douglas R. MacAYEAL ${ }^{2}$ \\ ${ }^{1}$ GESTAR, Cryospheric Sciences Laboratory, NASA Goddard Space Flight Center, Greenbelt, MD, USA \\ E-mail: kelly.m.brunt@nasa.gov \\ ${ }^{2}$ Department of Geophysical Sciences, University of Chicago, Chicago, IL, USA
}

\begin{abstract}
Three stations near the calving front of the Ross Ice Shelf, Antarctica, recorded GPS data through a full spring-neap tidal cycle in November 2005. The data revealed a diurnal horizontal motion that varied both along and transverse to the long-term average velocity direction, similar to tidal signals observed in other ice shelves and ice streams. Based on its periodicity, it was hypothesized that the signal represents a flow response of the Ross Ice Shelf to the diurnal tides of the Ross Sea. To assess the influence of the tide on the ice-shelf motion, two hypotheses were developed. The first addressed the direct response of the ice shelf to tidal forcing, such as forces due to sea-surface slopes or forces due to sub-ice-shelf currents. The second involved the indirect response of ice-shelf flow to the tidal signals observed in the ice streams that source the ice shelf. A finite-element model, based on viscous creep flow, was developed to test these hypotheses, but succeeded only in falsifying both hypotheses, i.e. showing that direct tidal effects produce too small a response, and indirect tidal effects produce a response that is not smooth in time. This nullification suggests that a combination of viscous and elastic deformation is required to explain the observations.
\end{abstract}

KEYWORDS: ice shelves, ice/ocean interactions

\section{INTRODUCTION}

GPS data collected near the seaward front of the Ross Ice Shelf, Antarctica (at stations NN, NS and R13 near a part of the Ross Ice Shelf referred to as 'Nascent Iceberg'; Fig. 1), in November 2005 indicated that the horizontal ice flow was modulated by the ocean tides (Brunt and others, 2010), which are strongly diurnal in the Ross Sea (Williams and Robinson, 1980; MacAyeal, 1984). This motion, over the course of a day, produced a flow rate acceleration and a deceleration, or a velocity variation, that was comparable in magnitude to the time-averaged annual mean flow (Fig. 2a).

Similar tidal signals have been observed in other ice shelves (Riedel and others, 1999; Doake and others, 2002; King and others, 2011; Makinson and others, 2012), ice streams (Anandakrishnan and Alley, 1997; Anandakrishnan and others, 2003; Bindschadler and others, 2003a,b; Gudmundsson, 2006, 2007; Murray and others, 2007), outlet glaciers (Marsh and others, 2013) and tidewater glaciers ( $\mathrm{O}^{\prime} \mathrm{Neel}$ and others, 2001). These studies used observation techniques to link horizontal motions in the ice to a causal mechanism involving the tide based on frequency. Most of these studies are either limited with respect to geographic extent or restricted to either the iceshelf or ice-stream regime.

Riedel and others (1999) observed a tide-induced horizontal displacement of the southern grounding zone of the Ekström Ice Shelf, in a 16 day GPS record (Fig. 1). Doake and others (2002) used a continuous, 30 day GPS record to examine the tide-induced, three-dimensional (3-D) motion of the Brunt Ice Shelf. They concluded that the observed variations in velocity might have been the result of basal friction, or drag, associated with tidal currents interacting with the underside of the ice shelf. However, the basal friction coefficients needed to justify this conclusion were found to be too high to be physically reasonable.
King and others (2011) collected longer (2 month to 2 year) GPS records from three sites on the Larsen $C$ ice shelf and observed semidiurnal, diurnal and fortnightly modulations in horizontal ice-flow velocity. They observed that at diurnal frequencies, the ice-shelf velocity varied by up to $\pm 100 \%$ from the time-averaged flow. Their model of this ocean/ice-shelf system suggested a nonlinear interaction between ocean tidal forcing and ice-flow response.

More recently, on the Ronne Ice Shelf, Makinson and others (2012) observed semidiurnal and diurnal velocity variations that reached $\pm 300 \%$ of the time-averaged flow. Their data came from a large campaign that included nine sites that sampled at periods ranging from 2 weeks to 1 year. Based on tidal phasing, tilt calculations and harmonic analysis, they concluded that the velocity variations were the result of an elastic response to tide-induced surface slope.

Various studies have observed tidal signals in the horizontal flow of the fast-moving West Antarctic ice streams that feed the Ross Ice Shelf (Fig. 1). Anandakrishnan and others (2003) observed smooth, periodic tidal modulations in the horizontal flow of Bindschadler Ice Stream (Fig. 2b). They found that the magnitude of the response decayed upstream, away from the grounding zone. Because the interaction between the ice shelf and the ice streams was not the main focus of their study, Anandakrishnan and others (2003) conceded that the influence of the ice shelf on the motion of the ice streams was poorly understood.

Bindschadler and others $(2003 a, b)$ and Wiens and others (2008) used GPS to investigate a tidal signal in the horizontal flow of Whillans Ice Stream (Fig. 2c). However, they observed the signal to have a quasi-periodic, 'stick-slip' motion. This motion changed from accelerations to decelerations on very short timescales, and was interpreted to be associated with subglacial conditions that are sensitive to 


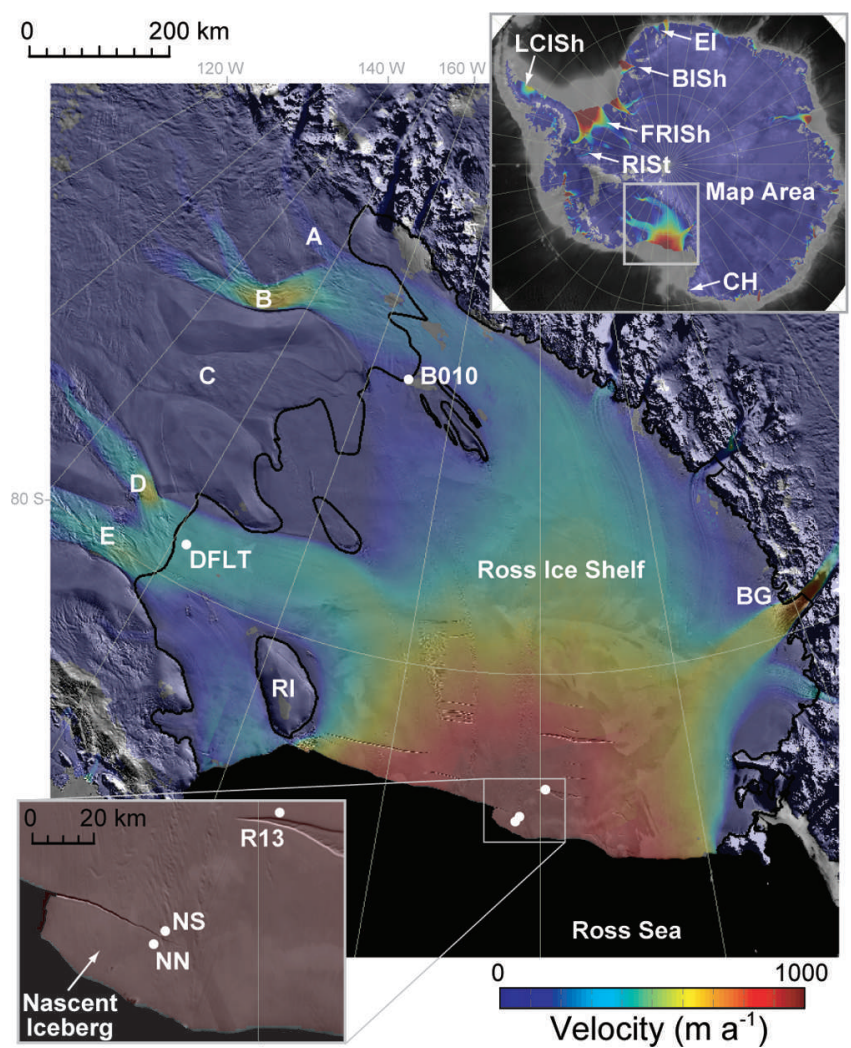

Fig. 1. Nascent Iceberg GPS stations (NN, NS and R13) on MODIS image (Scambos and others, 2007) and InSAR ice velocity (Rignot and others, 2011). Black line is MODIS grounding zone. Ekström (EI), Brunt (BISh), Larsen C (LCISh) and Filchner-Ronne (FRISh) ice shelves, Rutford (RISt), Mercer (A), Whillans (B), Kamb (C), Bindschadler (D) and MacAyeal (E) ice streams, Roosevelt Island (RI), Beardmore Glacier (BG), Cape Hallett $(\mathrm{CH})$ and sites B010 and DFLT are also indicated.

the state of the ocean tide in the Ross Sea Embayment. The pulsed ice-stream discharge involved a short-term cycle of stress accumulation and triggered stress release associated with sudden failure of subglacial till, which has been modeled as a plastic material (Winberry and others, 2009). The GPS measurements indicated that the pulsed ice-stream discharge occurred with a duration that is much smaller than a day ( $20 \mathrm{~min})$. The fact that these pulsations, typically two a day, were coordinated in time with the high or falling tide in the Ross Sea Embayment suggested that ocean tides influenced the dynamics of pulsed ice-stream flow.

Observations of tidal variations in grounded ice, upstream of the Ross Ice Shelf, are not limited to the fast-flowing West
Antarctic ice streams. Using GPS data, Marsh and others (2013) observed velocity variations on both sides of the grounding zone in the vicinity of Beardmore Glacier, an outlet glacier which is sourced from the East Antarctic ice sheet. Downstream of the grounding zone, the velocity varied by $50 \%$ from the time-averaged flow. However, once grounded, the velocity variation decayed rapidly, within $15 \mathrm{~km}$ of the grounding zone.

Tidal modulation of ice flow has been observed in relatively long GPS records on the Rutford Ice Stream, which feeds the Ronne Ice Shelf. Tides in this region are predominantly semidiurnal (Padman and others, 2002). In a study that extended both upstream and downstream of the Rutford Ice Stream grounding zone, Gudmundsson (2006) observed diurnal, semidiurnal and fortnightly tidal modulation in a 7 week GPS survey. Subsequently, Gudmundsson (2007) developed a model to investigate the relationship between the ice-flow modulation observed on fortnightly timescales and the basal shear-stress distribution upstream of the grounding zone, and concluded that the strong variation on the lunisolar synodic fortnightly tidal constituent (MSf) period (14.76 days) was the result of nonlinear interaction between the semidiurnal tidal constituents. Further, Gudmundsson (2007) concluded that other ice streams in the Filchner-Ronne Ice Shelf system were expected to have similar fortnightly flow variations. Ultimately, these observations and modeling efforts evolved into a coupled icestream and ice-shelf nonlinear basal sliding law (Gudmundsson, 2011). In a longer, 750 day GPS survey at a site $\sim 40 \mathrm{~km}$ upstream of the grounding zone, Murray and others (2007) reported tidal signals on semidiurnal, diurnal, fortnightly, semi-annual and annual periods. In each of the Rutford Ice Stream GPS surveys, the observed velocity variation was smooth and strongly correlated with the tides, similar to the signal observed on Bindschadler Ice Stream.

In light of investigations on other ice shelves and ice streams, the diurnal signal observed in the GPS data collected at Nascent Iceberg poses two compelling questions: What mechanism, or combination of mechanisms, associated with the tide generates the velocity variations observed at the front of the Ross Ice Shelf? If there are multiple forcing mechanisms, what is their relative significance?

\section{DATA}

\section{Nascent Iceberg GPS data}

GPS data were collected at the front of the Ross Ice Shelf at a site named 'Nascent Iceberg' $\left(78.1^{\circ} \mathrm{S}, 178.5^{\circ} \mathrm{W}\right)$, in close proximity to a large detachment rift, expected to eventually
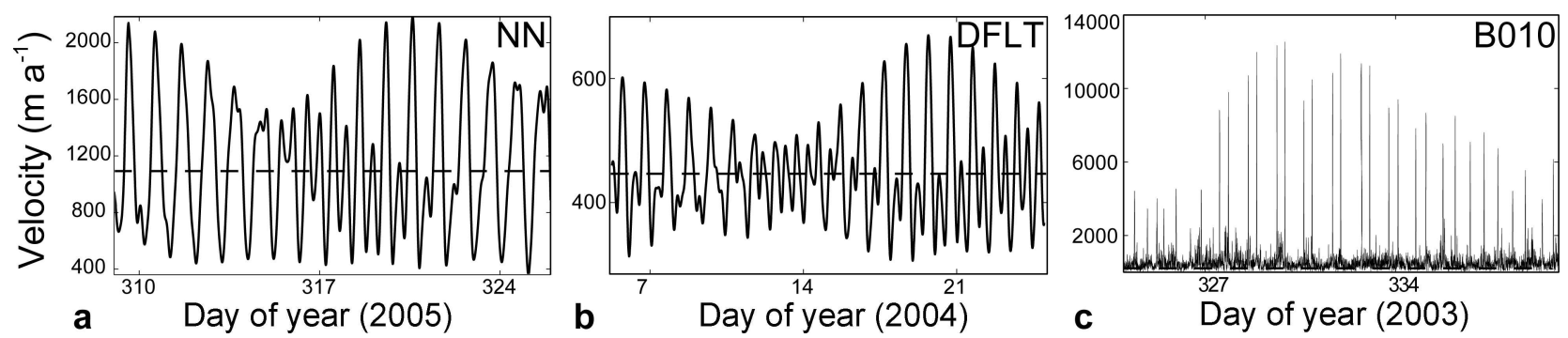

Fig. 2. Time series of ice-flow velocities (solid lines), fluctuating about the time-mean (dashed line), for (a) NN, (b) DFLT and (c) B010, based on GPS data spanning at least a full spring-neap tide cycle (Brunt and others, 2010). (Data for DFLT and B010, R. Bindschadler, personal communication, 2007. . 
yield an iceberg (Brunt and others, 2010). Two GPS stations were established, $4.2 \mathrm{~km}$ apart, on either side of the rift (Nascent North ('NN') and Nascent South ('NS'); Fig. 1). A third station (R13) was deployed $\sim 50 \mathrm{~km}$ inland from the rift. At each station, a dual-frequency GPS receiver sampled data continuously for at least 16 days.

The GPS data were processed using Precise Point Positioning techniques. The residual signal observed at each station in the filtered data, which included the removal of spurious outliers, and the smoothing and detrending of the full dataset, indicated smooth, sinusoidal motions corresponding to tidal frequencies (Fig. 2a). Furthermore, these motions were comparable to, or exceeded, the daily mean flow of the ice shelf derived from long-term averages of the GPS data (Brunt and others, 2010).

In comparison to GPS records from the West Antarctic ice streams, collected over a $\sim 75$ day period during the 2003/04 field season (personal communication from R. Bindschadler, 2007), the horizontal variations at Nascent Iceberg (Fig. 2a) were similar to the variations observed at Bindschadler Ice Stream (Fig. 2b). However, the tide-triggered stick-slip motion observed on Whillans Ice Stream was unique, where most of the ice flow occurred during two $20 \mathrm{~min}$ slip intervals over the course of a day (Fig. 2c).

\section{VISCOUS ICE-FLOW MODEL}

To investigate the possible cause of the tidal variation at Nascent Iceberg, a planar, two-dimensional viscous ice-flow model was created to examine the interaction between the Ross Ice Shelf and ocean tides. Following MacAyeal (1989), the physical basis of this model is a simplification of the 3-D stress-balance equations, often referred to as Stokes' equations, which make use of various assumptions associated with the creep of ice, assumed to obey Glen's flow law. Because the model employs a power-law creep rheology as opposed to an elastic rheology, we refer to it as a 'viscous' ice-flow model. The most important assumptions are that accelerations are negligible and that horizontal velocities $u$ and $v$ are independent of the vertical coordinate, $z$. These assumptions are also known as the shallow-shelf approximation. Under these assumptions, the governing equations are written in a manner here that includes tidal forcing terms:

$$
\begin{gathered}
\frac{\partial}{\partial x}\left[h \bar{\nu}\left(4 \frac{\partial u}{\partial x}+2 \frac{\partial v}{\partial y}\right)\right]+\frac{\partial}{\partial y}\left[h \bar{\nu}\left(\frac{\partial u}{\partial y}+\frac{\partial v}{\partial x}\right)\right]= \\
\rho_{\mathrm{i}} g\left(1-\frac{\rho_{\mathrm{i}}}{\rho_{\mathrm{w}}}\right) \frac{1}{2} \frac{\partial h^{2}}{\partial x}+\rho_{\mathrm{i}} g h \frac{\partial \eta}{\partial x}-\int_{b}^{s} \rho_{\mathrm{i}} \frac{\partial z}{\partial x} \mathrm{~d} z+\tau_{x} \\
\frac{\partial}{\partial x}\left[h \bar{\nu}\left(\frac{\partial v}{\partial x}+\frac{\partial u}{\partial y}\right)\right]+\frac{\partial}{\partial y}\left(h \bar{\nu}\left(4 \frac{\partial v}{\partial y}+2 \frac{\partial u}{\partial x}\right)\right)= \\
\rho_{\mathrm{i}} g\left(1-\frac{\rho_{\mathrm{i}}}{\rho_{\mathrm{w}}}\right) \frac{1}{2} \frac{\partial h^{2}}{\partial y}+\rho_{\mathrm{i}} g h \frac{\partial \eta}{\partial y}-\int_{b}^{s} \rho_{\mathrm{i}} \frac{\partial z}{\partial y} \mathrm{~d} z+\tau_{y}
\end{gathered}
$$

where $x$ and $y$ are horizontal coordinates, $z$ is the vertical coordinate, $u$ and $v$ are horizontal velocities, $\bar{\nu}$ is the depthaveraged effective viscosity, $h$ is the ice thickness, $\eta$ is a perturbation of the free ocean surface, $Z$ is the astronomical tide potential, $g$ is the gravitational constant, $\rho_{\mathrm{i}}$ and $\rho_{\mathrm{w}}$ are the densities of ice and sea water, taken to be 917 and $1028 \mathrm{~kg} \mathrm{~m}^{-3}$, respectively, and $\tau_{x}$ and $\tau_{y}$ are the basal shear stresses acting in the horizontal plane due to ocean currents.
Terms appearing on the left-hand side of Eqns (1) and (2) represent the divergence of the horizontal components of the deviatoric stress tensor within the vertical column of the ice shelf. All of these terms contain reference to the depthaveraged effective viscosity, $\bar{\nu}$, which is defined as a strainrate dependent function that represents Glen's flow law for ice (Glen, 1955). Glen's flow law treats ice as a nonlinear viscous material and states that ice strain rates are proportional to the deviatoric stress raised to the power $n$; with respect to the creep of ice, $n$ is generally taken to be 3 (e.g. Glen, 1958; Hooke, 1981).

The depth-averaged effective viscosity, $\bar{\nu}$, varies with the horizontal velocity components, $u$ and $v$, and with the temperature-dependent rate constant, often referred to as either the stiffness or flow-law parameter, $\bar{B}$. Values for $\bar{B}$ depend on thickness, $h$, and thus, are spatially variable. For this model application, values for $\bar{B}$ were prescribed based on MacAyeal and Thomas (1986).

Terms appearing on the right-hand side of Eqns (1) and (2) represent the forces that affect the flow of the ice shelf. The first term on the right-hand side of each equation represents the effect of the imbalance between sea-water pressure and ice pressure, which drives mean, timeindependent ice-shelf flow. It is common for ice-shelf models to be run with only this first term. The other three terms appearing on the right-hand side of Eqns (1) and (2) pertain to time-dependent tidal forcing. In the first case, sea-surface slopes are induced by the deformation of the free surface of the ocean, $\eta$, as the tidal perturbation passes beneath the ice shelf. In the second case, the astronomical tide-generating potential, $Z$, generates a horizontal force that pulls on the ice ever so slightly (Thomas, 2007). The last term on the right-hand side of each equation pertains to basal shear stress, $\tau$, associated with tide-induced ocean currents within the ice-shelf cavity.

Based on these governing equations, a finite-element model of the Ross Ice Shelf was created. The numerical domain of this model was a mesh composed of 1500 nodes that create 2700 triangular elements. The domain boundary of the model was based on the NASA Moderate Resolution Imaging Spectroradiometer (MODIS) Mosaic of Antarctica (Scambos and others, 2007). Where the domain boundary was in direct contact with grounded ice (e.g. ice streams or outlet glaciers), the associated nodes were designated as regions of 'inflow', and the horizontal velocities at these nodes were specified based on interferometric synthetic aperture radar (InSAR) methods of Rignot and others (2011) (Fig. 3a). This designation accounted for $20 \%$ of the boundary. Where the domain boundary was in direct contact with rock (e.g. adjacent to mountains), the horizontal velocity of the ice shelf at these nodes was initially specified to be zero, and conceptually represents 'no flow' across the grounding zone; this accounted for $60 \%$ of the boundary. Finally, on the seaward front of the domain, the total stress acting in the horizontal plane at the ice-front cliff was specified to be the vertically integrated pressure in the sea water beyond. These nodes were designated as 'outflow' and accounted for $20 \%$ of the boundary.

Ice thickness, $h$, varies spatially within the Ross Ice Shelf and was estimated based on the densities of ice and water, using British Antarctic Survey BEDMAP surface elevation data (Lythe and others, 2001) and assuming hydrostatic equilibrium. A constant value of $20 \mathrm{~m}$ was removed to approximate a firn correction. Ultimately, thickness results 


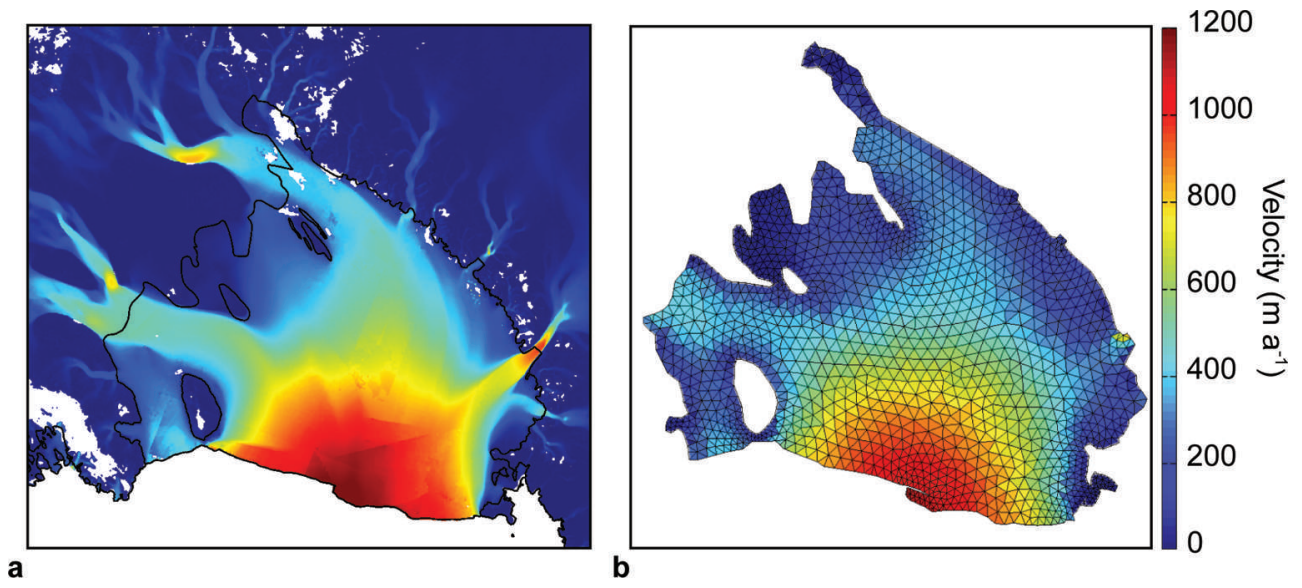

Fig. 3. (a) Velocity based on InSAR (Rignot and others, 2011) compared with (b) model-derived velocity, with finite-element mesh (black triangles) for reference.

based on hydrostatic assumptions compared well to radioecho sounding estimates of Neal (1979).

The finite-element model was then implemented in three distinct patterns of usage. In the first pattern, the steady-state, time-independent, ice-shelf flow was solved for under the assumption that time-dependent tidal forcing (e.g. the last three terms on the right-hand side of Eqns (1) and (2)) was absent. This model result was then used as a baseline to isolate the effects of the model results of the other two patterns of usage, which employ either direct or indirect tidal forcing. In the second pattern of model usage, the 'direct tidal forcing model', $Z$ was assumed zero (because of its small magnitude) and $\eta, \tau_{x}$ and $\tau_{y}$ in Eqns (1) and (2) were extracted from an ocean tidal model (Padman and others, 2003) and specified at each node through a full spring-neap tide cycle to produce a solution that varied through time. In the third pattern of model usage, the 'indirect tidal forcing model', the terms $Z, \eta, \tau_{x}$ and $\tau_{y}$ were assumed zero, but the ice flow along 'inflow' boundaries was specified to have a tidal variation, or stick-slip variation, depending on the model experiment. This means that the difference between the second and third patterns of model forcing was designed to differentiate the effects of forcing by the ocean acting directly on the ice shelf from the effects of the ice streams acting indirectly on the ice shelf. Ultimately, the Nascent Iceberg GPS data were used to interpret the model results of all three patterns of usage.

\section{Steady-state ice-shelf flow}

The first pattern of model usage, defined as the steady-state, time-independent, ice-shelf flow, was solved for under the assumption that time-dependent forcings were absent. Thus, the three terms appearing on the right-hand side of Eqns (1) and (2), that pertain to time-varying tidal forcing, were taken to be zero.

To ensure satisfaction of the power-law constitutive relation, the model iteratively solved for viscosity and horizontal velocity over the entire ice shelf using a prescribed initial value for depth-averaged effective viscosity, $\bar{\nu}$, and prescribed initial horizontal velocity components, $u$ and $v$, in regions of 'inflow' based on Rignot and others (2011). With an initial depth-averaged effective viscosity of $\bar{\nu}=1 \times 10^{17} \mathrm{~N} \mathrm{sm}^{-2}, 25$ iterations were needed for the model to converge on solutions for viscosity and velocity.
The model results for $\bar{\nu}$ ranged from $10^{13}$ to $10^{17} \mathrm{~N} \mathrm{~s} \mathrm{~m}^{-2}$, with a mean value of $9.8 \times 10^{14} \mathrm{~N} \mathrm{~s} \mathrm{~m}^{-2}$.

The model result for steady-state, time-independent, iceshelf flow (Fig. 3b) confirmed that equations, input data, mesh resolution and coding were consistent with the mean state of ice-shelf flow. Specifically, model results for velocity were compared to the InSAR velocities of Rignot and others (2011) (Fig. 3a) and the time-mean ice-shelf velocity based on GPS data collected at Nascent Iceberg. The model was tuned solely using the $20 \mathrm{~m}$ approximated firn correction, and ultimately derived a horizontal velocity at Nascent North of $1093.87 \mathrm{ma}^{-1}$, comparing well to the value of $1093.59 \mathrm{~m} \mathrm{a}^{-1}$ based on the GPS data.

\section{Direct, tide-forced, ice-shelf flow model}

Tides of the Ross Ice Shelf are strongly diurnal (Williams and Robinson, 1980; MacAyeal, 1984), with maximum tidal amplitudes occurring near the grounding zones, specifically in the vicinity of Mercer Ice Stream (Fig. 1), where the total amplitude range is $>3 \mathrm{~m}$ (Padman and others, 2003). The tidal perturbation rotates clockwise under the floating Ross Ice Shelf like a Kelvin wave, around a diurnal amphidromic point located off the coast near Cape Hallett (MacAyeal, 1984) and a weaker semidiurnal amphidromic point beneath the northwestern part of the Ross Ice Shelf (Williams and Robinson, 1980).

The tidal amplitude, or perturbation of the free surface, $\eta$, in Eqns (1) and (2), represents small changes in height across the ice shelf. Given the scale of the Ross Ice Shelf $(\sim 800 \mathrm{~km}$ on each side), at any one time, some regions are experiencing high tide, while others are experiencing low tide. Variable heights across the ice shelf will create regional surface slopes; these slopes may be substantial enough to induce accelerated and decelerated ice flow. The term in Eqns (1) and (2) containing $Z$ describes the astronomical tide-generating potential, the effect of which is equivalent to putting the ice shelf on an inclined ocean surface, induced by the equilibrium tide. Based on Platzman (1984), the equilibrium tide has an amplitude of $0.1 \mathrm{~m}$ and, due to the diurnal nature of the tides in the Ross Sea Embayment, a very large phase variation, equivalent to half the distance around the circumference of the globe, which is of order $10000 \mathrm{~km}$ at $75-85^{\circ} \mathrm{S}$. In contrast, sea-surface tidal amplitudes for the Ross Sea Embayment are on the order of $1 \mathrm{~m}$ and vary on 

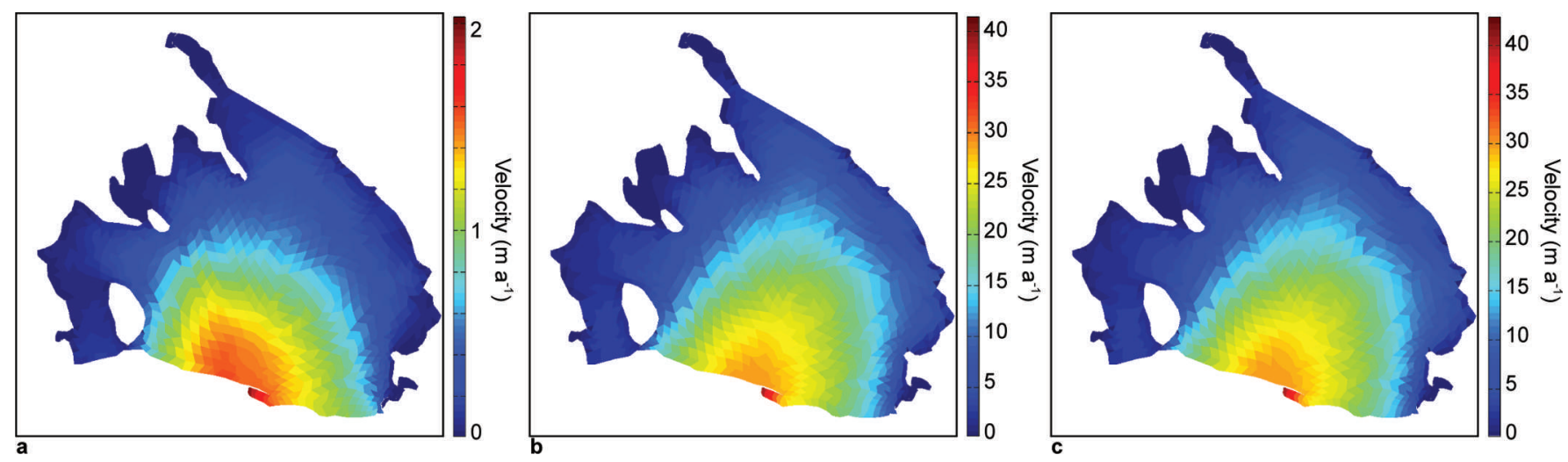

Fig. 4. An element-by-element difference between the velocity baseline (Fig. 3b) and (a) the influence of $\tau$, (b) $\eta$ and (c) the combined influence of $\tau$ and $\eta$, representing the direct, tide-forced velocity.

length scales of $1000 \mathrm{~km}$. Thus, the theoretical slope associated with the term containing $Z$ was disregarded as it is 100 times smaller than the term associated with seasurface slope, containing $\eta$. The last term in Eqns (1) and (2), containing $\tau$, is associated with basal friction resulting from the interaction between the base of the ice shelf and the ocean currents within the ice-shelf cavity. Robertson and others (1998) define the basal shear stresses due to ocean currents in the $x$ and $y$ directions within the ice-shelf cavity, $\tau_{x}$ and $\tau_{y}$, as

$$
\begin{aligned}
\tau_{x} & =\frac{C_{D} \rho_{\mathrm{w}} U_{\mathrm{w}}\left|\boldsymbol{U}_{\mathrm{w}}\right|}{H^{2}} \\
\tau_{y} & =\frac{C_{D} \rho_{\mathrm{w}} V_{\mathrm{w}}\left|\boldsymbol{U}_{\mathrm{w}}\right|}{H^{2}},
\end{aligned}
$$

where $C_{D}$ is the coefficient of friction taken to be 0.003 from Robertson and others (1998), $\rho_{\mathrm{w}}$ is the density of water, $U_{w}$ and $V_{\mathrm{w}}$ are the horizontal tidal transports within the ice-shelf cavity, $\boldsymbol{U}_{\mathrm{w}}$ is the magnitude of the volume water transport vector $\left(\left|\boldsymbol{U}_{\mathrm{w}}\right|=\sqrt{U_{\mathrm{w}}^{2}+V_{\mathrm{w}}^{2}}\right)$, and $H$ is the water column thickness under the ice shelf.

Equations (1) and (2) required the specification of $\eta$ and $\tau$, through time, at each node in the finite-element mesh. The free surface, $\eta$, was extracted directly from the Ross Sea Height-Based Tidal Inverse Model ('Ross_Inv_2002') (Padman and others, 2003), which represents a high-resolution finite-difference model for the Ross Sea, ideal for predicting heights for the Ross Ice Shelf. The ocean tide model has $\sim 10 \mathrm{~km}$ resolution and its accuracy is optimized by the assimilation of data from ten gravimetric tide gauges on the Ross Ice Shelf. Accuracy is likely to be at the $\mathrm{cm}$ level for $\eta$. Similarly, to determine the basal shear stress, $\tau$, the water column thickness, $H$, which is based on the seismic and radar analysis, and horizontal tidal transports within the iceshelf cavity, $U_{w}$ and $V_{w}$, were also extracted from the ocean tide model and then applied to Eqns (3) and (4).

Once variables from the tide model were extracted, the direct tide-forced, time-dependent, ice-shelf flow model was iterated to solve for viscosity and velocity. This process was repeated, with a time step of 2 hours, for the 17 day length of the GPS record, or through slightly more than one springneap tidal cycle.

The influence of tide-induced basal friction, or drag $(\tau)$, and that of tide-induced sea-surface slope (associated with $\eta$ ) on the flow of the ice shelf were initially examined separately. To uniquely examine the effect of drag on the flow of the ice shelf in the absence of forcing associated with slope, a series of model velocity fields was generated for the entire Ross Ice Shelf, with one field associated with each 2 hour time step. A 'maximum drag-forced model velocity field' was created by extracting the maximum drag-forced model velocity of each element, independent of when it occurred during the tidal cycle. The steady-state solution (Fig. 3b) of each element was then subtracted from this 'maximum drag-forced model velocity field' to isolate the maximum velocity fluctuation associated with $\tau$ (Fig. 4a). The effect of tide-induced sea-surface slope (associated with $\eta$ ) on the flow of the ice shelf, in the absence of forcing associated with drag $(\tau)$, was similarly isolated (Fig. 4b).

A series of model velocity fields to test the collective influence of both $\tau$ and $\eta$ was generated to ultimately assess the direct, tide-forced ice-shelf flow model. A 'maximum model velocity field' was created by extracting the maximum model velocity of each element, independent of when it occurred during the tidal cycle. The steady-state solution (Fig. 3b) of each element was then subtracted from this 'maximum model velocity field' to isolate the maximum velocity fluctuation associated with both tide-induced surface slope and basal drag (Fig. 4c).

From Figure $4 a$ and $b$, the influence of $\tau$, which peaked at $2.0 \mathrm{~m} \mathrm{a}^{-1}$, was an order of magnitude less than the influence of $\eta$, which peaked at $41.4 \mathrm{ma}^{-1}$. Further, the forcing associated with $\eta$ is symmetric, while the influence of $\tau$ was not. The maximum response of both sea-surface slope and basal drag occurred along the front of the ice shelf. For the slope forcing, this occurred in the vicinity of Nascent Iceberg. However, the maximum response associated with drag forcing moved along the front of the ice shelf depending on time. After high tide, the maximum response occurred in the vicinity of Roosevelt Island and then migrated toward Nascent Iceberg. This migration was likely due to the fact that, as discussed previously, the tidal perturbation rotates clockwise under the floating Ross Ice Shelf around an amphidromic point.

Based on model results, the collective effect of both tideinduced surface slope and basal drag (Fig. 4c) was not enough to account for the variations observed at Nascent Iceberg. The maximum contribution from the direct tidal forcing was taken to be the difference between (1) the maximum value of each element over the full spring-neap tidal cycle and (2) the baseline velocity (Fig. 4). The maximum difference, which occurred in the vicinity of 
a

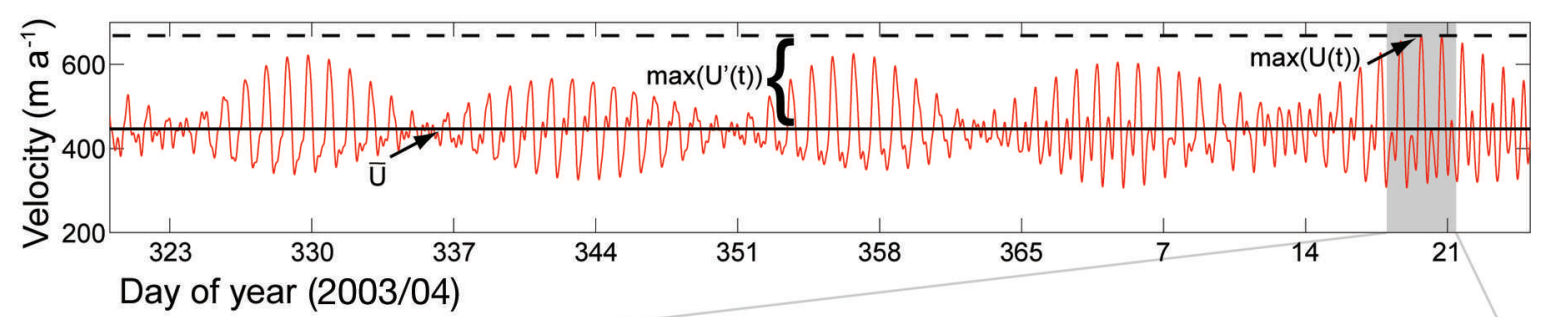

b

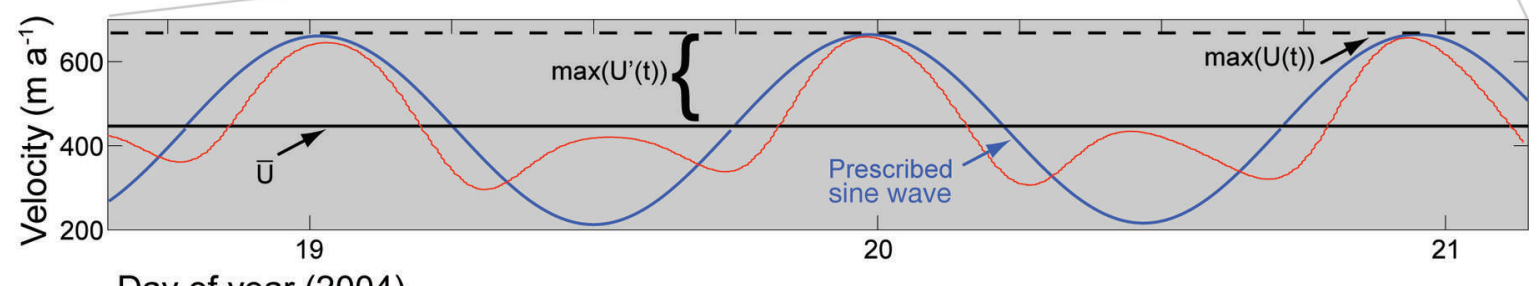

Fig. 5. (a) $\boldsymbol{U}(t)$ observed at DFLT (red line), where $\overline{\boldsymbol{U}}$ (black solid line) and $\max (\boldsymbol{U}(t))$ (black dashed line) are used to prescribe a sine wave to the ice-stream forced flow model. (b) A detailed view of the period 19-21 January 2004 (shaded gray box in (a)) indicates the form of the prescribed sine wave (blue line).

Nascent Iceberg, was $\sim 42.9 \mathrm{~m} \mathrm{a}^{-1}$, or $<5 \%$ of the $1000 \mathrm{~m} \mathrm{a}^{-1}$ velocity variation observed in the GPS data (Fig. 2a). Thus, based on this viscous flow model, tide-induced surface slope and basal drag were insufficient to explain the magnitude of the velocity fluctuations observed at the front of the Ross Ice Shelf.

\section{Indirect, ice-stream forced, ice-shelf flow model}

To examine the indirect tidal influence on the ice-shelf flow model, i.e. forcing associated with a time-dependent variation in 'inflow' from the ice streams, Eqns (1) and (2) were solved for under the assumption that time-dependent forcings were absent with a modified set of boundary conditions. Specifically, the velocities of regions of 'inflow' associated with the ice streams were allowed to vary through time based on the magnitude and character (either sinusoidal or stick-slip) of the West Antarctic ice-stream GPS data (Fig. 2b and c). The velocities of regions of 'inflow' associated with the outlet glaciers were specified based on the InSAR velocities of Rignot and others (2011) and held constant.

The full ice-flow velocity, $\boldsymbol{U}(t)$, unique to each ice stream, is defined as

$$
\boldsymbol{U}(t)=\overline{\boldsymbol{U}}+\boldsymbol{U}^{\prime}(t)
$$

where $\bar{U}$ is the time-independent, mean velocity of the ice stream, and $\boldsymbol{U}^{\prime}(t)$ is the time-dependent part of the velocity field that is dominated by the tide (Fig. 5a). The mean component, $\overline{\boldsymbol{U}}$, was calculated from the ice-stream GPS data using the least-squares method. The magnitude of $\bar{U}$ in the vicinity of the grounding zone varied between ice streams from near-zero to $\sim 400 \mathrm{~m} \mathrm{a}^{-1}$. The time-dependent velocity, $\boldsymbol{U}^{\prime}(t)$, was tabulated using 21 tidal constituents based on a similar study on Rutford Ice Stream by Murray and others (2007). Given that the ice-stream GPS dataset was collected over $\sim 75$ days, long-period tidal variation is evident in $\boldsymbol{U}^{\prime}(t)$. The magnitude of $\boldsymbol{U}^{\prime}(t)$ varied substantially between the ice streams from near zero to $\sim 10000 \mathrm{~m} \mathrm{a}^{-1}$, depending on the character of the ice-stream flow (either sinusoidal or stick-slip; Fig. 2b and c, respectively).
Bindschadler Ice Stream was observed to have a smooth, diurnal, sinusoidal $\boldsymbol{U}^{\prime}(t)$ (Fig. 2b). However, observed $\bar{U}$ at its grounding zone was extremely high, resulting in a large $\boldsymbol{U}(t)$. The character of the velocity variation observed in this ice stream matched the diurnal, sinusoidal motion observed at Nascent Iceberg; however, the magnitude of the variation was amplified at the ice-shelf front (Fig. 2a and b). Whillans Ice Stream was observed to have a tide-triggered, stick-slip $\boldsymbol{U}^{\prime}(t)$. The slip events were very brief (two $20 \mathrm{~min}$ slip intervals per day), but during those slip events, velocity observations were on the order of $10000 \mathrm{ma}^{-1}$; velocity between slip events was observed to be approximately zero (Fig. 2c).

For this model experiment, the 'inflow' velocities for Mercer, Kamb, Bindschadler and MacAyeal ice streams were varied sinusoidally based on the ice-stream GPS data. Specifically, the mean velocities, $\overline{\boldsymbol{U}}$, were modified by defining a simplified sinusoid around that value (Fig. 5b), with a maximum amplitude limited by the percent change between $\boldsymbol{U}(t)$ and the maximum full velocity derived from the GPS data, unique to each ice stream, i.e. $\max (\boldsymbol{U}(t))=\overline{\boldsymbol{U}}+\max \left(\boldsymbol{U}^{\prime}(t)\right)$. Observations of tidetriggered, stick-slip $\boldsymbol{U}^{\prime}(t)$ have thus far been limited to Whillans Ice Stream (Bindschadler and others, 2003a,b). Therefore, stick-slip motion in the model was only prescribed to this ice stream. Values of 'inflow' associated with the outlet glaciers were based on the initial InSAR velocities and held constant.

Based on model results, the indirect ice-stream forcing was not enough to account for the variations observed at Nascent Iceberg. The maximum contribution from the indirect ice-stream forcing was taken to be the difference between (1) maximum model velocity of each element over all 'time steps' and (2) the baseline velocity (Fig. 6), and is greatest in the vicinity of Whillans Ice Stream. At the front of Ross Ice Shelf, this value was $580 \mathrm{~m} \mathrm{a}^{-1}$, or $\sim 50 \%$ velocity fluctuation observed in the GPS data collected at Nascent Iceberg (Fig. 2a). Relative to the results of the surface slope and basal friction model, the magnitude of the response of the ice-stream forced model was considerably larger. 


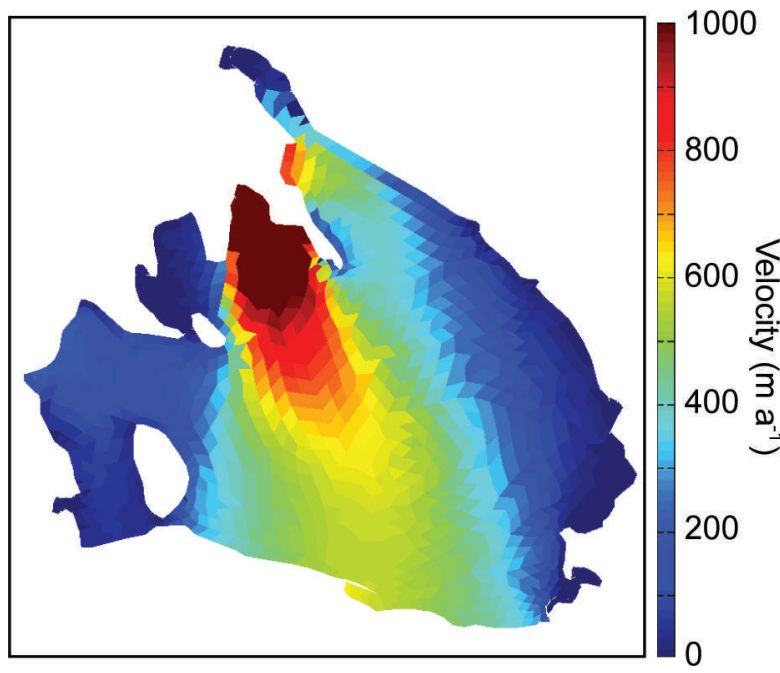

Fig. 6. The difference between the indirect, stick-slip (for Whillans Ice Stream only) and sinusoidal (all other ice streams) stream-forced model velocity maximum of each element and the velocity baseline (Fig. 3b).

However, the model velocity field at Nascent Iceberg spiked in response to the stick-slip model forcing at the Whillans Ice Stream region of 'inflow'. Thus, the character of the model response at Nascent Iceberg did not match the smooth, periodic observations of the GPS record.

\section{DISCUSSION}

The two sets of experiments conducted here have failed to simultaneously predict the magnitude and the smooth, periodic nature of the observed variations in ice velocity at the front of the Ross Ice Shelf. The model results associated with tide-induced surface slopes and basal friction generally reproduced the smooth, diurnal nature of the observations at Nascent North (cf. Figs 2a and 7a); however, this model application does not reproduce the magnitude of the observations. Conversely, the model results associated with tidal variation of ice-stream 'inflow' velocities generally produced larger-magnitude variations, relative to the direct, tide-forced, ice-shelf flow model (cf. Figs 2a and 7b); however, this model application does not reproduce the smooth character of the observations. To elicit the smooth, sinusoidal variation of the ice-shelf flow at Nascent Iceberg, the discharge across the grounding line of Whillans Ice Stream would also have to be smooth and sinusoidally varying, not stick-slip. Also, the amplitude of this discharge would have to be much higher than observed, and higher even than the amplitude at Nascent Iceberg, because the amplitude pattern decays downstream of the input boundaries. Ultimately, in the case of tidal forcing due to seasurface slopes or due to sub-ice-shelf currents, the viscous stress regime of the ice shelf is too stiff to allow an appropriately large strain rate demanded by the GPS observations at Nascent Iceberg. These results nullify the two hypotheses posed above, but yield a firm conclusion that 'viscous'-style flow responses to the tidal forcing, either indirect or direct, must be augmented by other rheological processes to explain the GPS data.

Harmonic analysis of GPS data from the Ronne Ice Shelf (Makinson and others, 2012) suggested that tide-induced surface slope alone was capable of producing the observed
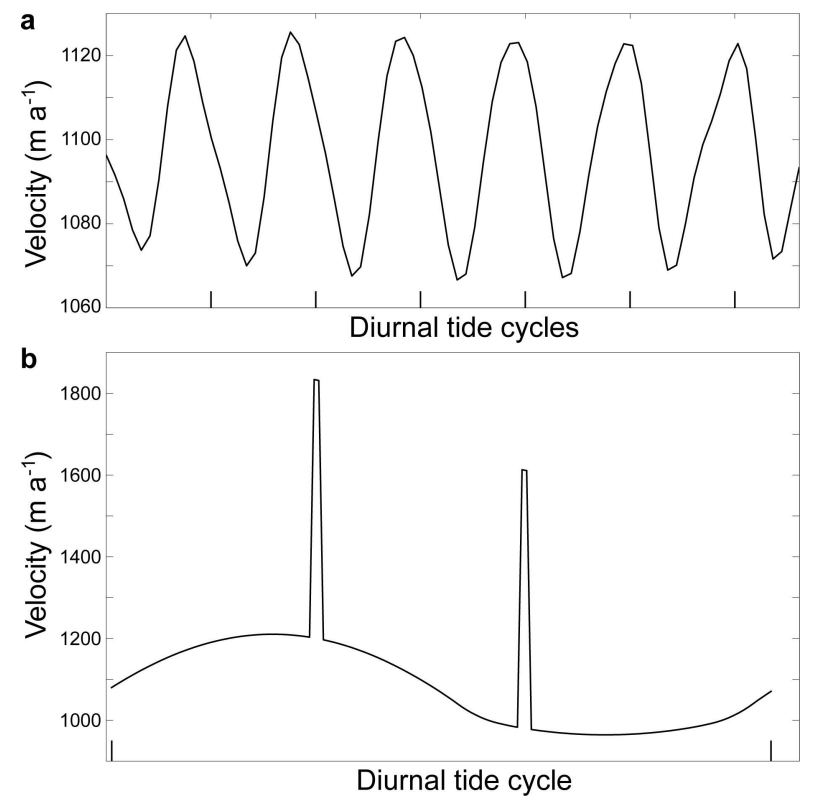

Fig. 7. The magnitude and character of model velocity at Nascent Iceberg for (a) direct tidal forcing (response to surface slope and basal friction) and (b) indirect tidal forcing (response to changes in 'inflow' from the ice streams) for at least one tidal cycle. Note the changes in the $y$-axes.

$\pm 300 \%$ semidiurnal and diurnal velocity variations around the time-averaged ice-shelf flow. Their conclusions also minimized the effect of basal drag, mostly based on phasing arguments. Further, based on the temperature of the ice and modeling efforts of Gudmundsson (2007), they concluded that the Ronne Ice Shelf responds as an elastic membrane at tidal timescales.

Given the results of Makinson and others (2012), and given that the character of the model results associated with tide-induced surface slopes and basal friction more closely matched the smooth nature of the velocity variations at Nascent Iceberg, we conclude that this model provides the viscous component of a viscoelastic ice-flow model, which assumes that ice behaves as a Maxwell material. The smooth, periodic nature of the signal observed at Nascent Iceberg further suggests that some component of elastic response must be dampening the stick-slip signal observed at Whillans Ice Stream.

The timescale, $t$, of viscoelastic relaxation of a Maxwell material is characterized by

$$
\boldsymbol{t}=\frac{\nu}{E},
$$

where $E$ is the Young's modulus, taken to be $4.8 \mathrm{GPa}$ based on modeling efforts of Gudmundsson (2011), and $\nu$ is the effective viscosity, taken to be $9.8 \times 10^{14} \mathrm{~N} \mathrm{~s} \mathrm{~m}^{-2}$ based on the mean depth-averaged effective viscosity, $\bar{\nu}$, determined by the Ross Ice Shelf flow model. The relaxation time is therefore on the order of a day, or roughly tidal timescales. Therefore, we conclude that the inclusion of a viscous component, and the incorporation of an elastic component, in our model is appropriate for assessing ice-flow response to tidal forcing.

For a Maxwell material, the total strain of the system $\left(\varepsilon_{\text {total }}\right)$ is the sum of the viscous and elastic strains $\left(\varepsilon_{\text {viscous }}\right.$ and $\left.\varepsilon_{\text {elastic }}\right)$ on each element:

$$
\varepsilon_{\text {total }}=\varepsilon_{\text {viscous }}+\varepsilon_{\text {elastic. }}
$$


Under this assumption, the viscous ice-flow model presented here has determined the component associated with the viscous response $\left(\varepsilon_{\text {viscous }}\right)$; the elastic component $\left(\varepsilon_{\text {elastic }}\right)$ can now be solved independently, or in series, with respect to the viscous component. Ultimately, we conclude that adding the elastic component to the existing ice-shelf flow model will capture the magnitude of the signal observed at Nascent Iceberg while simultaneously explaining the downstream loss, or dampening, of the signal observed at Whillans Ice Stream.

\section{CONCLUSIONS}

Two weeks of GPS data were collected at the front of the Ross Ice Shelf and contained a diurnal signal, assumed to be associated with the tide. A viscous ice-flow model, using the nonlinear viscosity implied by Glen's flow law, was created to assess the relative significance of direct and indirect tidal forcing mechanisms based on the response observed at the front of the Ross Ice Shelf. Specifically, model experiments were designed to independently quantify the effects of (1) tide-induced surface slopes and basal friction, and (2) tide-modulated flow of the ice streams. In general, the model response to tide-induced surface slopes and basal friction matched the character of the observations at Nascent Iceberg, but was too small in amplitude. While the response to tide-modulated flow of the ice streams more closely matched the magnitude of the observations at Nascent Iceberg, the temporal variation of the response in the model was not smooth enough to match the observations. These two experiments suggest that there is no possible way to force a viscous treatment of the ice shelf to match observations, and that some additional aspect of ice rheology must come into play in order to explain the observations.

Ultimately, the effect of the tide-induced slope of the ice shelf, coupled with the effect of basal drag associated with tidal currents in the ice-shelf cavity, amounted to $<5 \%$ of the horizontal velocity variation observed at Nascent Iceberg. However, based on the analysis and conclusions of Makinson and others (2012), this model represents the viscous component of a viscoelastic ice-flow model, where the solution for the elastic component can be added to this result, under the assumption that ice behaves as a Maxwell material. Modeling and understanding the periodicity and sensitivities of ice-shelf flow will illuminate factors associated with the long-term stability of ice shelves. Further, a better understanding of the mechanisms controlling the tidal signals on this ice shelf may provide insight into the mechanisms at play across the grounding zone, within the complex regime of the ice streams.

\section{ACKNOWLEDGEMENTS}

We thank R. Bindschadler for ice-stream GPS data; M. King and L. Copland for GPS data analysis; E. O'Donnell, J. Thom, L.M. Cathles, O. Sergienko, M. Okal, T. Wagner, Kenn Borek Air, the University Navstar Consortium (UNAVCO) and the US Antarctic Program for field support; R. Walker for helpful discussions; and two anonymous reviewers for constructive comments that greatly improved the manuscript. This work was supported by US National Science Foundation grants OPP-0229546 and ANT-0944193, NASA Science Innovation Fund and NASA Cryospheric Sciences Laboratory.

\section{REFERENCES}

Anandakrishnan S and Alley RB (1997) Tidal forcing of basal seismicity of Ice Stream C, West Antarctica, observed far inland. J. Geophys. Res., 102(B7), 15183-15196 (doi: 10.1029/97JB01073)

Anandakrishnan S, Voigt DE, Alley RB and King MA (2003) Ice Stream $\mathrm{D}$ flow speed is strongly modulated by the tide beneath the Ross Ice Shelf. Geophys. Res. Lett., 30(7), 1361 (doi: 10.1029/2002GL016329)

Bindschadler RA, King MA, Alley RB, Anandakrishnan S and Padman L (2003a) Tidally controlled stick-slip discharge of a West Antarctic ice stream. Science, 301(5636), 1087-1089 (doi: 10.1126/science.1087231)

Bindschadler RA, Vornberger PL, King MA and Padman L (2003b) Tidally driven stick-slip motion in the mouth of Whillans Ice Stream, Antarctica. Ann. Glaciol., 36, 263-272 (doi: 10.3189/ 172756403781816284)

Brunt KM, King MA, Fricker HA and MacAyeal DR (2010) Flow of the Ross Ice Shelf, Antarctica, is modulated by the ocean tide. J. Glaciol., 56(195), 157-161 (doi: 10.3189/ 002214310791190875)

Doake CSM and 6 others (2002) Tide-induced lateral movement of Brunt Ice Shelf, Antarctica. Geophys. Res. Lett., 29(8), 1226 (doi: 10.1029/2001GL014606)

Glen JW (1955) The creep of polycrystalline ice. Proc. R. Soc. London, Ser. A, 228(1175), 519-538 (doi: 10.1098/rspa. 1955.0066)

Glen JW (1958) The flow law of ice: a discussion of the assumptions made in glacier theory, their experimental foundation and consequences. IASH Publ. 47 (Symposium at Chamonix 1958 Physics of the Movement of the Ice), 171-183

Gudmundsson GH (2006) Fortnightly variations in the flow velocity of Rutford Ice Stream, West Antarctica. Nature, 444(7122), 1063-1064 (doi: 10.1038/nature05430)

Gudmundsson GH (2007) Tides and the flow of Rutford Ice Stream, West Antarctica. J. Geophys. Res., 112(F4), F04007 (doi: 10.1029/2006JF000731)

Gudmundsson GH (2011) Ice-stream response to ocean tides and the form of the basal sliding law. Cryosphere, 5(1), 259-270 (doi: 10.5194/tc-5-259-2011)

Hooke RLeB (1981) Flow law for polycrystalline ice in glaciers: comparison of theoretical predictions, laboratory data, and field measurements. Rev. Geophys. Space Phys., 19(4), 664-672 (doi: 10.1029/RG019i004p00664)

King MA, Makinson K and Gudmundsson GH (2011) Nonlinear interaction between ocean tides and the Larsen $\mathrm{C}$ Ice Shelf system. Geophys. Res. Lett., 38(8), L08501 (doi: 10.1029/ 2011GL046680)

Lythe MB, Vaughan DG and BEDMAP consortium (2001) BEDMAP: a new ice thickness and subglacial topographic model of Antarctica. J. Geophys. Res., 106(B6), 11 335-11351 (doi: 10.1029/ 2000JB900449)

MacAyeal DR (1984) Numerical simulations of the Ross Sea tides. J. Geophys. Res., 89(C1), 607-615 (doi: 10.1029/ JC089iC01p00607)

MacAyeal DR (1989) Large-scale ice flow over a viscous basal sediment: theory and application to Ice Stream B, Antarctica. J. Geophys. Res., 94(B4), 4071-4087 (doi: 10.1029/ JB094iB04p04071)

MacAyeal DR and Thomas RH (1986) The effects of basal melting on the present flow of the Ross Ice Shelf, Antarctica. J. Glaciol., 32(110), 72-86

Makinson K, King MA, Nicholls KW and Gudmundsson GH (2012) Diurnal and semidiurnal tide-induced lateral movement of Ronne Ice Shelf, Antarctica. Geophys. Res. Lett., 39(10), L10501 (doi: 10.1029/2012GL051636)

Marsh OJ, Rack W, Floricioiu D, Golledge NR and Lawson W (2013) Tidally induced velocity variations of the Beardmore Glacier, Antarctica, and their representation in satellite 
measurements of ice velocity. Cryosphere, 7(5), 1375-1384 (doi: 10.5194/tc-7-1375-2013)

Murray T, Smith AM, King MA and Weedon GP (2007) Ice flow modulated by tides at up to annual periods at Rutford Ice Stream, West Antarctica. Geophys. Res. Lett., 34(18), L18503 (doi: 10.1029/2007GL031207)

Neal CS (1979) The dynamics of the Ross Ice Shelf revealed by radio echo-sounding. J. Glaciol., 24(90), 295-307

O'Neel S, Echelmeyer KA and Motyka RJ (2001) Short-term flow dynamics of a retreating tidewater glacier: LeConte Glacier, Alaska, U.S.A. J. Glaciol., 47(159), 567-578 (doi: 10.3189/ 172756503781830430)

Padman L, Fricker HA, Coleman R, Howard S and Erofeeva L (2002) A new tide model for the Antarctic ice shelves and seas. Ann. Glaciol., 34, 247-254 (doi: 10.3189/ 172756402781817752)

Padman L, Erofeeva S and Joughin I (2003) Tides of the Ross Sea and Ross Ice Shelf cavity. Antarct. Sci., 15(1), 31-40 (doi: 10.1017/ S0954102003001032)

Platzman GW (1984) Normal modes of the world ocean. Part IV: Synthesis of diurnal and semidiurnal tides. J. Phys. Oceanogr., 14(10), 1532-1550 (doi: 10.1175/1520-0485(1984)014<1532: NMOTWO $>2.0 . \mathrm{CO} ; 2)$

Riedel B, Nixdorf U, Heinert M, Eckstaller A and Mayer C (1999) The response of the Ekströmisen (Antarctica) grounding zone to tidal forcing. Ann. Glaciol., 29, 239-242 (doi: 10.3189/ 172756499781821247)
Rignot E, Mouginot J and Scheuchl B (2011) Ice flow of the Antarctic Ice Sheet. Science, 333(6048), 1427-1430 (doi: 10.1126/science.1208336)

Robertson R, Padman L and Egbert GD (1998) Tides in the Weddell Sea. In Jacobs SS and Weiss RF eds. Ocean, ice and atmosphere: interactions at the Antarctic continental margin. (Antarctic Research Series 75) American Geophysical Union, Washington, DC, 341-369

Scambos TA, Haran TM, Fahnestock MA, Painter TH and Bohlander J (2007) MODIS-based Mosaic of Antarctica (MOA) data sets: continent-wide surface morphology and snow grain size. Remote Sens. Environ., 111(2-3), 242-257 (doi: 10.1016/ j.rse.2006.12.020)

Thomas RH (2007) Tide-induced perturbations of glacier velocities. Global Planet. Change, 59(1-4), 217-224 (doi: 10.1016/ j.gloplacha.2006.11.017)

Wiens DA, Anandakrishnan S, Winberry JP and King MA (2008) Simultaneous teleseismic and geodetic observations of the stickslip motion of an Antarctic ice stream. Nature, 453(7196), 770-774 (doi: 10.1038/nature06990)

Williams RT and Robinson ES (1980) The ocean tide in the southern Ross Sea. J. Geophys. Res., 85(C11), 6689-6696 (doi: 10.1029/ JC085iC11p06689)

Winberry JP, Anandakrishnan S, Alley RB, Bindschadler RA and King MA (2009) Basal mechanics of ice streams: insights from the stick-slip motion of Whillans Ice Stream, West Antarctica. J. Geophys. Res., 114(F1), F01016 (doi: 10.1029/2008JF001035) 